\title{
Family Environment as Perceived by Adolescent Boys and Girls
}

\author{
Shanti Balda ${ }^{1}$, Sheela Sangwan $^{1}$ and Arti Kumari ${ }^{2 *}$ \\ Department of Human Development and Family Studies, I.C. College of Home Science, \\ CCS HAU Hisar-125004, India \\ *Corresponding author
}

\section{Keywords}

Cohesion, expressiveness, Acceptance, independence, Active-recreational orientation, Organization, Control, Family environment, Rural, Urban, Adolescent, Boys, Girls

Article Info

Accepted: 14 December 2018 Available Online: 10 January 2019

\section{A B S T R A C T}

The present study was conducted in Hisar city and two villages of Hisar district. Two Government Senior Secondary Schools (one for boys and one for girls) from rural area and two Government Senior Secondary Schools (one for boys and one for girls) from Hisar city were selected at random. The study was conducted with 16-18 years old adolescents. These adolescents were selected from randomly selected four Government Senior Secondary Schools. Total sample constituted of 240 adolescents, 120 from rural area and 120 from urban area. These 240 adolescents included 120 boys and 120 girls. Family environment was assessed with the help of Family Environment Scale (FES) by Bhatia and Chadha (2004). Fathers of majority of adolescents had education up to senior secondary level, while majority of mothers had education up to middle school level. Maximum number of adolescents belonged to lower income group followed by middle and high income groups. Adolescents were personally interviewed about their perception of family environment. Z-test was used to determine if there were statistically significant differences between family environment perceived by rural and urban adolescent boys and girls. Results revealed that urban adolescents perceived family environment as more cohesive, more expressive, more accepting and caring, and more independent as compared to rural adolescents. While, rural adolescents perceived family environment more organized than urban adolescents. Urban adolescents perceived family environment significantly much better than those from rural area. Adolescent boys perceived family environment as more expressive, more accepting and caring, more independent, while, adolescents girls perceived family environment as more organized and controlling. Adolescent boys perceived family environment significantly much better than adolescent girls. Findings of the present study are useful for parents and caregivers of adolescents.

\section{Introduction}

Family environment is the quality and quantity of socio-emotional support and understanding that parents provide to their children within the home. Bhatia and Chadha (2004) have illustrated eight aspects of family environment- cohesion, expressiveness, conflict, acceptance and caring, independence, active-recreational orientation, organization, and control. Cohesion is degree of commitment, help, and support family members provide for one another. Expressiveness is extent to which family 
members are encouraged to act openly and express their feelings and thoughts directly. Acceptance and caring is extent to which the members are unconditionally accepted and degree to which caring is expressed in family. Conflict is amount of openly expressed aggression and conflict among family members. Independence is extent to which the members are assertive and independently make their own decisions. Active-recreational orientation is extent of participation in social and recreational activities. Organization is degree of importance of clear organization structure in planning family activities and responsibilities. Control is degree of limit setting within a family.

Buehler and Gerard (2013) described the importance of family as a key socialization context for children as they move through early adolescence. Within this complex socialization context there are potential family risk factors that may create adjustment problems for adolescents. Risk factors include socioeconomic conditions of the family, parents' psychological condition, marital relationship, and parenting skills. Cumulative risk was related with boys' higher externalizing problems and with girls' increased externalizing problems. These factors were also associated with adjustment difficulties during adolescence. Kamble (2014) also mentioned that family is major socialization agency and has great influence and bearing on the behavior of children.

Although adolescents are becoming independent physically, emotionally and cognitively, but they are still in growing stage. They need a secure home base for optimum development and particularly during tough times. Parent-adolescent child relationship and caring role of parents is extremely important. Besides being authoritative parenting, parents need to develop a more collaborative approach with their adolescent children. This is important to build a strong relationship between the two. Positive relationship between parents and their adolescent children acts as a protective factor for socio-emotional wellbeing of adolescents.

Prevatt (2003) examined a risk and resiliency model of children's adjustment and results revealed significant relationship between mother's reports of both family conflict and child behavior problems. Youngblade et al., (2007) have reported that negative relationships and interactions between parents and adolescents may result in conflict and there is probability that adolescents are likely to engage in risk behaviors during adolescence and later life.

Family is the basic unit and interactions among family members are termed as transactions and can be positive or negative. Healthy family environment results in positive transactions; while negative environment leads to negative transactions. The family environment involves the circumstances and social climate conditions within families. The family environments can differ in many ways, for example, on the basis of socio-economic level and parenting practices (Zastrow and Kirst-Ashman, 2013). Keeping in view the ways in the importance of family environment the present study was planned to assess the family environment as perceived by rural and urban adolescent boys and girls. It was hypothesized that rural and urban adolescents; and adolescent boys and girls will perceive their family environment in a similar manner.

\section{Methodology}

\section{Locale of the study and sample selection}

The study was conducted in rural and urban area of Hisar district of Haryana state. Two senior secondary schools providing coeducation were selected randomly from rural 
areas and similarly two co-educational senior secondary schools from Hisar city were selected at random. Sixty adolescents (30 boys and 30 girls) were selected from each school, thus, constituting a sample of 240 adolescents, 120 from rural area and 120 from Hisar city. Mean age of boys was 17.1 years and that of girls was 17.5 years.

\section{Measures and Method for Data Collection}

Boys and girls from rural and urban area were interviewed for their perception of family environment with the help of Family Environment Scale (FES) by Bhatia and Chadha (2004). The FES consists of 69 items and is scored on a five-point scale strongly agrees (5) to strongly disagree (1). This measure has eight subscales - Cohesion, Expressiveness, Conflict, Acceptance and Caring, Independence, Active-Recreational Orientation, Organization, and Control. The scale has seven positive subscales- cohesion, expressiveness, acceptance, independence, active-recreational orientation, organization and control; and one negative aspect, that is, conflict. Higher scores indicate better family environment. For conflict subscale of family environment, higher score means low conflicts in the family and lower scores means high conflicts in the family. Three categories were made on the basis of standard deviation- low, average and high. Total scores were also computed for family environment.

\section{Results and Discussion}

Z-test was computed to examine differences in adolescents' perception regarding their family environment on the basis of their area of residence and sex.

Comparison of family environment as perceived by rural and urban adolescents

As presented in Table 1, there were significant differences in perception of adolescents regarding cohesion in urban $($ Mean $=50.73)$ and rural (Mean=48.21) families, $\mathrm{z}=2.02$, $\mathrm{p}<.05$. Also, significant differences were observed for expressiveness in urban and rural families (Means=33.74 and 31.37 respectively), $\mathrm{z}=2.38, \quad \mathrm{p}<.01$. Regarding acceptance and caring attitude, significant differences were observed among urban $($ Mean=47.52) and rural $($ Mean=43.57) families, $\mathrm{z}=3.09, \mathrm{p}<.01$ as perceived by adolescents. Urban adolescents perceived significantly more independence $($ Mean=36.10) than rural adolescents (Mean=32.88), $\mathrm{z}=4.06, \mathrm{p}<.01$. While on the other hand, rural adolescents perceived family environment more organized (Mean=7.95) than urban adolescents (Mean=6.85), $\mathrm{z}=4.41$, $\mathrm{p}<.01$. Significant differences were also found for overall family environment, $\mathrm{z}=3.22, \mathrm{p}<.01$. Urban adolescent perceived family environment better (Means=261.80) than rural adolescents (249.99).

It can be interpreted from these findings that, urban adolescents perceived more cohesion in families than those from rural area. Urban adolescents perceived that they were allowed to express their feelings and thoughts freely and that they perceived more accepting and caring attitude as compared to rural adolescents. Urban adolescents perceived family environment as more independence, while rural adolescents perceived family environment more organized. Overall, urban adolescents perceived family environment better than rural adolescents. Hence, the hypothesis cannot be accepted that urban and rural children perceive the family environment in the similar manner.

\section{Comparison of family environment as perceived by adolescent boys and girls}

As depicted in Table 2, significant differences were observed for expressiveness by adolescent boys and girls (Means $=33.86$ and 31.26 respectively), $\mathrm{z}=2.64, \mathrm{p}<.01$. Regarding 
acceptance and caring attitude, significant differences were observed among adolescent boys (Mean=47.62) and girls (Mean=43.47), $\mathrm{z}=3.25, \mathrm{p}<.01$. Adolescent boys perceived significantly more independence (Mean=35.60) than adolescent girls (Mean=33.88), $\mathrm{z}=2.75, \mathrm{p}<.01$. Adolescent girls perceived family environment more organized (Mean=7.75) than adolescent boys (Mean=7.07), $\mathrm{z}=2.67, \mathrm{p}<.01$. Significant differences were also found for control in family environment as perceived by adolescent boys and girls, $\mathrm{z}=2.59, \mathrm{p}<.01$; girls perceived more control than boys (Means $=14.90$ and 15.78 respectively). Significant differences were also found for overall family environment, $\mathrm{z}=3.22, \mathrm{p}<.01$. Adolescent boys perceived family environment better (Means=259.39) than adolescent girls (252.40).

It can be interpreted from these findings that adolescent boys perceived more expressiveness, acceptance and caring attitude and more independence in families than girls. On the other hand, girls perceived family environment more organized and perceived that there was more control than adolescent boys. Overall, adolescent boys perceived family environment better than adolescent girls. Hence, the hypothesis cannot be accepted that adolescent boys and adolescent girls perceive the family environment in the similar manner.

Results of the present research revealed that urban adolescents perceived more cohesion in their families than those from rural area. Urban adolescents perceived that they were allowed to express their feelings and thought freely and that they perceived more accepting and caring attitude as compared to rural adolescents. Urban adolescents perceived family environment as more independence than rural adolescents. Overall, urban adolescents perceived family environment better than rural adolescents.
This means that there was commitment and support for each other in the urban families. The family members were encouraged to express their feelings and thoughts freely. Also family members unconditionally accepted, were caring for each other and promoted more independence among their adolescent children. Overall, urban adolescents perceived family environment much better than rural adolescents.

That urban adolescents perceived family environment much better, one of the explanation could be that urban parents were economically better and had more educational exposure, hence could promote better environment in their families in comparison to rural parents. These results get support from Saini (2013), Pinki (2015) and Bala (2018). These authors also found that urban children perceived their family environment much better as compared to rural children. In another study, Grolinck et al., (1997) indicated that more educated parents could provide better home environment to their children as they are more skilled for getting involved in different activities with their children. Halle et al., (1997) mentioned that parents from poor economic background lack the skill and resources for providing a cordial home environment to their children.

Rural adolescents perceived their family environment more organized than urban adolescents. It means that rural adolescents perceived that in their families importance was given to clear organization structure in planning family activities and responsibilities. One of the reasons could be that rural parents were authoritarian in parenting hence believed in more organization and enforcing more responsibilities related to household activities. On the other hand urban parents might be flexible and could be authoritative in parenting and hence could be less organized. Similar findings have been reported by Bala (2018) 
that in comparison to urban adolescents, rural adolescents perceived that in their families importance was given to clear organization structure in planning family activities and responsibilities.

Results further revealed that male adolescents perceived family environment as more expressive with acceptance and caring attitude and perceived more independence than their female counterparts. Overall, adolescent boys perceived family environment better than adolescent girls.

It can be interpreted from these results that boys were encouraged to act openly and express their feelings and thoughts directly as compared to girls. Also they were encouraged more for personal growth through acceptance and caring attitude and independence; and through participation in social and recreational activities. One of the reasons could be that in Indian culture greater importance is given to sons, hence they are given more independence and allowed to participate in social and recreational activities than their female counterparts. Similar findings have been reported by Pinki (2015) and Bala (2018) indicating that boys perceived better quality of family environment as compared to girls. Boys were given more opportunities for participation in social and recreational activities and independence to make their own choices in comparison to girls. Verma and Ghadially (1985) also reported that male children received more independence and encouragement than females because of cultural roles assigned to both the sexes in adult life.

Results also revealed that female adolescents perceived family environment as more organized and controlling as compared to male adolescents.

It can be inferred from these results that female adolescents perceived that they participated in more in planning family activities and household related responsibilities.

Table.1 Comparison of family environment as perceived by rural and urban adolescents

\begin{tabular}{|c|c|c|c|}
\hline \multirow{2}{*}{$\begin{array}{l}\text { Sub-scales of } \\
\text { family } \\
\text { environment }\end{array}$} & \multicolumn{2}{|c|}{ Area } & \multirow[t]{2}{*}{ z-value } \\
\hline & $\begin{array}{c}\text { Urban }(n=120) \\
\text { Mean } \pm \text { SD }\end{array}$ & $\begin{array}{c}\text { Rural }(n=120) \\
\text { Mean } \pm \text { SD }\end{array}$ & \\
\hline Cohesion & $50.73 \pm 8.62$ & $48.21 \pm 6.63$ & $2.02 *$ \\
\hline Expressiveness & $33.74 \pm 5.94$ & $31.37 \pm 9.05$ & $2.38 * *$ \\
\hline Conflict & $42.87 \pm 9.50$ & $41.65 \pm 8.19$ & 0.96 \\
\hline $\begin{array}{l}\text { Acceptance } \\
\text { and caring }\end{array}$ & $47.52 \pm 7.51$ & $43.57 \pm 9.63$ & $3.09 * *$ \\
\hline $\begin{array}{l}\text { Active } \\
\text { recreational } \\
\text { orientation }\end{array}$ & $28.52 \pm 4.58$ & $29.12 \pm 5.52$ & 0.90 \\
\hline Independence & $36.10 \pm 4.95$ & $32.88 \pm 5.12$ & $4.06^{* *}$ \\
\hline Organization & $6.85 \pm 2.05$ & $7.95 \pm 1.80$ & $4.41 * *$ \\
\hline Control & $15.46 \pm 2.28$ & $15.21 \pm 2.81$ & 0.72 \\
\hline $\begin{array}{l}\text { Overall family } \\
\text { environment }\end{array}$ & $261.80 \pm 20.53$ & $249.99 \pm 24.52$ & $3.22 * *$ \\
\hline
\end{tabular}


Table.2 Comparison of family environment as perceived by adolescent boys and girls

\begin{tabular}{|l|c|c|c|}
\hline $\begin{array}{l}\text { Sub-scales of } \\
\text { family } \\
\text { environment }\end{array}$ & $\begin{array}{c}\text { Boys }(\mathbf{n = 1 2 0}) \\
\text { Mean } \pm \text { SD }\end{array}$ & $\begin{array}{c}\text { Girls }(\mathbf{n = 1 2 0}) \\
\text { Mean } \pm \text { SD }\end{array}$ & z-value \\
\hline Cohesion & $49.12 \pm 8.55$ & $49.82 \pm 8.63$ & 0.55 \\
\hline Expressiveness & $33.86 \pm 6.91$ & $31.26 \pm 8.05$ & $2.64 * *$ \\
\hline Conflict & $41.87 \pm 9.58$ & $42.65 \pm 8.23$ & 0.62 \\
\hline $\begin{array}{l}\text { Acceptance } \\
\text { and caring }\end{array}$ & $47.62 \pm 7.82$ & $43.47 \pm 9.54$ & $3.25^{* *}$ \\
\hline $\begin{array}{l}\text { Active } \\
\text { recreational } \\
\text { orientation }\end{array}$ & $29.36 \pm 5.27$ & $28.28 \pm 5.16$ & 1.59 \\
\hline Independence & $35.60 \pm 5.27$ & $33.88 \pm 6.12$ & $2.75^{* *}$ \\
\hline $\begin{array}{l}\text { Organization } \\
\text { Control }\end{array}$ & $14.07 \pm 2.06$ & $7.75 \pm 1.89$ & $2.67 * *$ \\
\hline $\begin{array}{l}\text { Overall family } \\
\text { environment }\end{array}$ & $259.39 \pm 26.14$ & $252.40 \pm 25.35$ & $1.88^{*}$ \\
\hline Significant at $* * \mathbf{p}<.01$ and $* \mathbf{p}<.05$ & level of significance. \\
\hline
\end{tabular}

They also perceived that family environment as more controlling as compared to male respondents. Here also reason could be that in Indian culture girls are given more training for preparing them for their future role to bear the responsibilities of their families after their marriage. More limits are set for them so that they can be prepared for their adult role in life. Similar results were reported by Pinki (2015) and Bala (2018) indicating that girls scored high on organization and control aspects of family environment as compared to boys. Finding of the present study are contradictory to the findings of Mohanraj and Latha (2005) who reported that boys perceived more control in their families i.e., they perceived that their family has set rules and emphasized on following rules in the family.

Conclusion and suggestions are as follows:

It can be concluded that family environment play a crucial role in adolescents' development. The results of a study conducted by Dasgupta and Sanyal (2008) also revealed that family environment with the provision of unconditional love and acceptance had positive impact on behavioural management skills of children. Family serves as an enriching ground for early socialization and personality development of children and adolescents.

It can be said that urban adolescents perceived more cohesion, expressiveness, acceptance and caring attitude and independence as compared to rural adolescents. While rural adolescents perceived family environment as more organized. Overall, urban adolescents perceived family environment better than their rural counterparts. Regarding sex differences, boys perceived more expressiveness, acceptance and caring attitude and more independence in their families as compared to girls. On the other hand, girls perceived family environment more organized and perceived more control than adolescent boys. Overall, adolescent boys perceived family environment better than adolescent girls. Since parental relationship and their caring role with their adolescent child 
continue to be important, hence they need to be flexible in dealing with adolescents and should use more authoritative and collaborative approach. Parents and caregivers should be made aware about the importance of positive parenting strategies as a protective factor against the development of psycho-social problems in their adolescent children, particularly for their adolescent girls.

\section{Acknowledgment}

The authors would like to thank the school authorities for providing consent for conducting the research with students and would like to thank the respondents who participated in this research and provided their valuable time. The authors acknowledge the infrastructure and support of CCS HAU, Hisar for carrying out this research.

\section{References}

Bala, M. (2018). Family environment and psycho-social problems among adolescents. Unpublished M.Sc. thesis. Department of Human Development and Family Studies, I.C. College of Home Science, CCSHAU, Hisar.

Bhatia, H. and Chadha, N. K. 2004. Family Environment Scale. National Psychological Corporation, Agra.

Buehler, C. and Gerald, J.M. (2013). Cumulative family risk predicts increases in adjustment difficulties across early adolescence. Journal of Youth and Adolescence, 42(6):905-20.

Dasgupta, M., and Sanyal, N. 2008. Family, the chief catalyst in promoting children's emotional wellbeing: A review, Indian Journal of Community Psychology, 4(1): 48-63.

Grolnick, W.S., Benjet, C., Kurowick, C.O. and Apostoleries, N.H. 1997. Predictors of parent involvement, in: Children's schooling. Journal of Educational Psychology, 89(3): 538-548.

Halle, T.G., Costes, B.K. and Mahoney, J.L., 1997, Family influence on school achievements in low-income African, American children. Journal of Educational Psychology, 29(3): 527537.

Kamble, S.M. 2014. Impact of family environment on academic performance: The need of social work intervention. Indian Streams Research Journal, 3(12): $1-6$.

Mohanraj, R. and Latha (2005). Perceived family environment in relation to adjustment and academic achievement, Journal of the Indian Academy of Applied Psychology, 31(1-2): 18-23.

Pinki (2015). Attitude of adolescents towards modernization. Unpublished M.Sc. Thesis. Department of Human Development and Family Studies, I.C. College of Home Science, CCSHAU, Hisar.

Prevatt, F. 2003. The contribution of parenting practices in a risk and resiliency model of children's adjustment. British Journal of Developmental Psychology, 21: 469480.

Saini, V. (2013). Parenting style as determination of children's behavior. Unpublished M.Sc. Thesis. Department of Human Development and Family Studies, I.C. College of Home Science, CCSHAU, Hisar.

Verma, R.K. and Ghadialy, R. 1985. Effect of mother's sex role attitude on needs for achievements and expectancy for success in children. Psychological Studies, 30 (1):1-4.

Youngblade, L. M., Theokas, C., Schulenberg, J., Curry, L., Huang, I., and Novak, M. 2007. Risk and promotive factors in families, schools, and communities: A contextual model 
of positive youth development in adolescence. Pediatrics, 119: S47-S53.

Zastrow, C., and Kirst-Ashman, K. K. 2013.
Understanding Human Behavior in the Social Environment, Australia; Belmont, CA: Brooks/Cole. (WHO).

\section{How to cite this article:}

Shanti Balda, Sheela Sangwan and Arti Kumari. 2019. Family Environment as Perceived by Adolescent Boys and Girls. Int.J.Curr.Microbiol.App.Sci. 8(01): 2262-2269. doi: https://doi.org/10.20546/ijcmas.2019.801.237 